\title{
A Study of 42 Cases of Pott's Paraplegia with Anterior Spinal Decompression \& Stabilisation with Rib Graft Alone
}

\author{
${ }^{1}$ Dr.M.Sri Ranga Rao, ${ }^{2}$ Dr. A. Padmaja, ${ }^{3}$ Dr. V. S. Ravindranath, \\ ${ }^{1}$ Assistant Professor, Osmania Medical College, Hyderabad, Telangana. \\ ${ }^{2}$ Assisstant Professor, Osmania Medical College, Hyderabad. \\ ${ }^{3}$ Professor I/C, Department of Orthopaedics, Osmania Medical College, Hyderabad.
}

\begin{abstract}
:
Background: Spinal tuberculosis is mostly secondary to either Pulmonary or Abdominal lesions, and may result in Paraplegia either due to pressure effects of the cold abscess or due to collapse of the vertebra. Most of the patients with Grade I and II paraparesis respond well to chemotherapy, while Grade III and IV patients and some of the patients in Grade I and II who do not respond to chemotherapy need Spinal decompression to prevent irreparable damage to the Spinal who did not respond to 3-4 weeks of chemotherapy and rest or deteriorated during treatment. They were treated by anterior trans-thorasic and trans-pleural spinal decompression by partial or total carpectomy depending on the extent of involvement of the bodies and anterior spinal fusion using rib graft alone, during the period Feb. 2007 to May 2014, in Government General and Chest hospital, Osmania Medical College, Hyderabad.
\end{abstract}

Results: Out of 42 patients complete neurological recovery was seen in 40 patients, 1 patient had partial recovery while 1 patient died of post-operative complications.

Conclusions: Anterior spinal decompression and stabilization using rib graft alone is a good choice of surgical treatment in terms of neurological recovery, healing of the lesion, and is a cost-effective treatment option for the patient. Post-operative rehabilitation is also early.

Keywords: Pott's paraplegia, anterior decompression, Rib graft.

\section{Introduction}

This entity was first described by Percival Pott in 1782. The management of spinal tuberculosis has evolved through various eras of management, from drugs alone, radical surgery combined with drugs, to the current era of drug treatment in majority of patients with surgery limited to those with specific indications.

According to WHO $1 / 3$ of world population is infected with Tuberculosis. One fifth of TB population is in India. Skeletal Tuberculosis contributes 3\% of total cases. Vertebral tuberculosis is the most common type of skeletal tuberculosis. (Fig 1, \& 2)

Males and females are equally effected. Neurological complications are most crippling complications of spinal tuberculosis (incidence $20 \%$ ).

Pott's disease is usually secondary to an extra-spinal source of infection. Most of the times the primary site may be lung, visceral or glandular. It is due to Heamatogenous spread. The area affected usually is the anterior aspect of the vertebral body adjacent to the sub-chondral plate. The contiguous vertebrae are involved usually but rarely skip lesions are encountered (fig 4).

\section{Materials And Methods}

This study is conducted at Govt. gen. \& chest hospital, Hyderabad b/w the period of February 2007may2014. This study includes 42 cases of pott's paraplegia treated with anterior trans-thoracic trans-pleural approach to the spine with complete or partial corpectomy with rib graft.

Neurological examination is done. Plain radiograph is taken two months after the surgery (Table 2).

Patient is mobilised with help of TAYLOR"S BRACE 3months after the surgery.

Patient is reviewed at $6,12,15,18,24$ months. MRI is taken at $6,12,18$ months post op. ATT continued for 18 moths post operatively, 4 drug regime for 4 months which includes HRZE (INH, Rifampicin, Pyrazinamide and Ethambutol). 3 drug regime for 14 months which includes HRE (INH, Rifampicin, Ethambutol).

\section{Results}

This study was conducted between February 2007 to May 2014 at Government General and Chest Hospital, Hyderabad, with an average follow up of 3.5 yrs. (5. 5 yrs-- 1.5 yrs.). Out of 42 Patients 24 are Male 
and 18 are Female (Graph 1) Age incidence: Most of the patients are between 20-40 years of age. (Graph 2) Most commonly involved region of dorsal spine is D6-D7, followed by D9-D10 (Graph 3) Average operative time was $2 \mathrm{hrs}$. Average blood loss of 500ml. No intra operative complications are observed.1 patient developed drug reaction (Nausea, skin rash, abdominal discomfort) but did not warrant stoppage of ATT. out of 42 patients with paraplegia complete neurological recovery is seen in 40 patients. In this study Partial recovery is seen in 1 patient. Post- operatively one patient developed respiratory embarrassment and was put on ventilator but unfortunately patient succumbed.

\section{Results of the study are followed as:}

Excellent result: Complete resolution of disease with DOTS regimen for 18 months, with no residual disability or deformity with solid bony union.

Good result: Complete resolution of disease with DOTS regimen for 18 months with no residual disability or deformity and with the occurrence of medically manageable mild pain, however not limiting physical activity with no neurological deficit.

Fair result: Complete resolution of disease, but with a post treatment kyphosis deformity of 30 degrees or more at the affected level, with partial neurological recovery, or patients who are having moderate residual pain limiting their physical activity.

Poor result: Failure to achieve bony union or no neurological improvement or death due to complications.

Out of 34 patients, 32 patients showed excellent results, one patient showed fair result.

One patient showed poor result (Graph 4).

\section{Discussion}

Radical debridement and decompression remains the standard surgical procedure for removal of disease which needs additional structural support using rib graft. Rib graft is used as auto graft after spinal decompression as a strut. Successful incorporation of strut graft allowed early axial loading and mobilization of the patient. The autogenous rib graft also helps in enhancing osteo-genic potential. Frequently, the spinal tuberculosis often involves 2 or more number of vertebral bodies in dorsal and dorso-lumbar region. However, involvement and destruction of 3 or more vertebral bodies needs more rigid and stable fixation. Autogenous iliac crests and fibular strut grafts can be used in patients who require most stable fixation.

Study done by S. Govender et al., by using allogenic bone grafts for stabilization of anterior column showed similar results, all the patients achieved complete neurological recovery and significant bony union.

Most common cause of paraplegia in tuberculous spine is inflammatory edema of the cord, followed by mechanical compression due to tuberculous granulation tissue. Intra operatively it was observed that clearance of granulation tissue relieved mechanical pressure on cord and post operatively helped in neurological recovery.

The earlier the initiation of the treatment, the better is the result. If the treatment is started during the pre -destructive or early destructive stages, the results are excellent or good, however, in the later stages of kyphosis with involvement of more vertebrae, the results start becoming fair or poor. The destroyed tissues can never attain the pre-disease level this explains the better results in those patients treated in the early stages of the disease.

\section{Conclusion}

Anterior spinal decompression and fusion using rib graft for tuberculosis of the spine was highly successful in producing significant neurological recovery, and Solid bony fusion. Good clinical outcomes as well as improvement of neurological functions are achieved. Graft slippage is not a problem with autologous rib graft if properly inserted. But correction of kyphotic deformity in two or more vertebrae disease was not satisfactory and requires larger bone grafts and instrumental fixation.

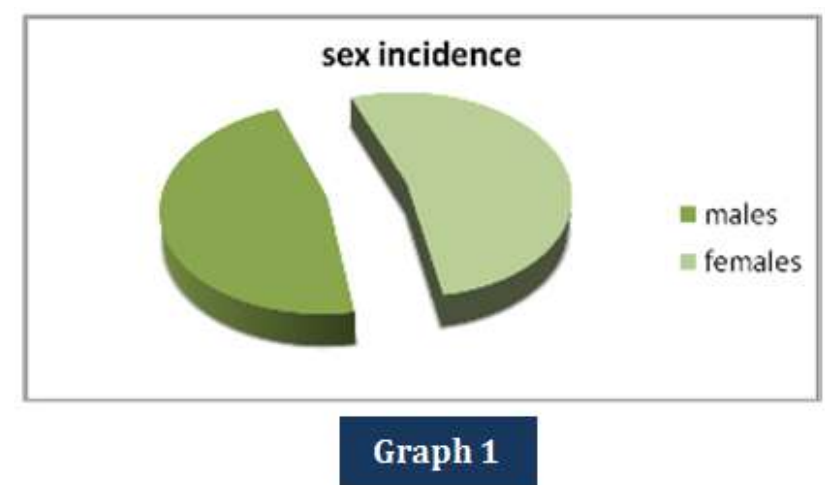




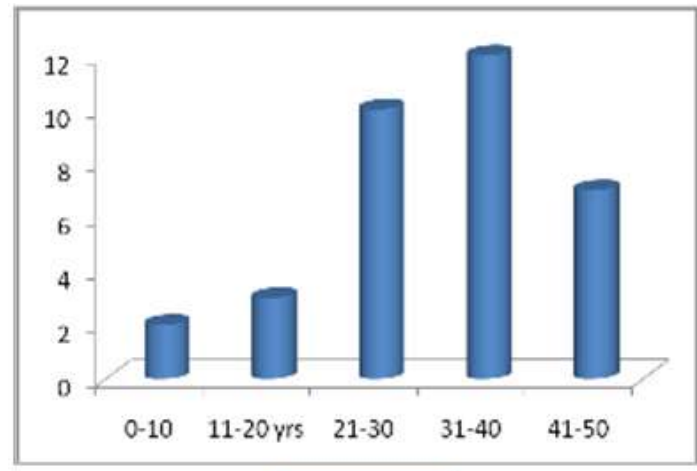

\section{Graph 2}

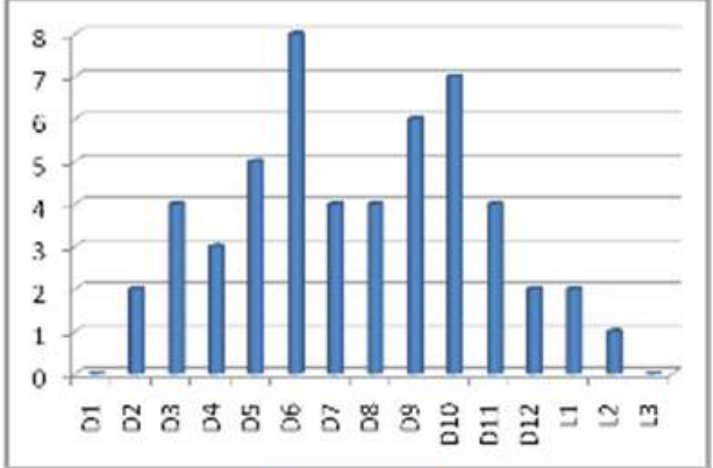

Graph 3

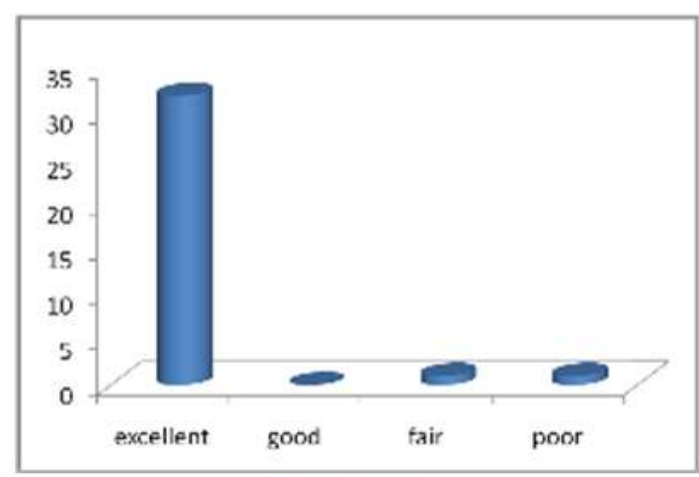

Graph 4

Intra-Operative Pictures:

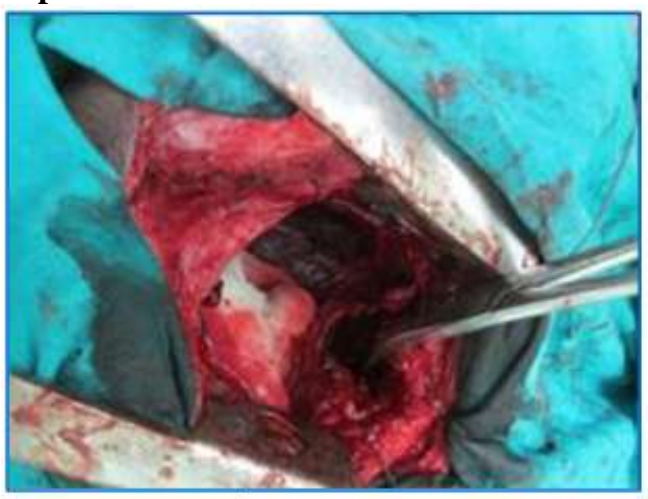

Fig. 1

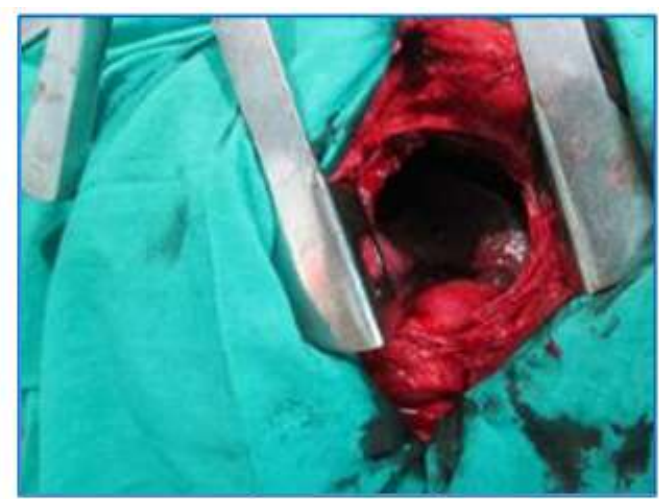

Fig. 2 


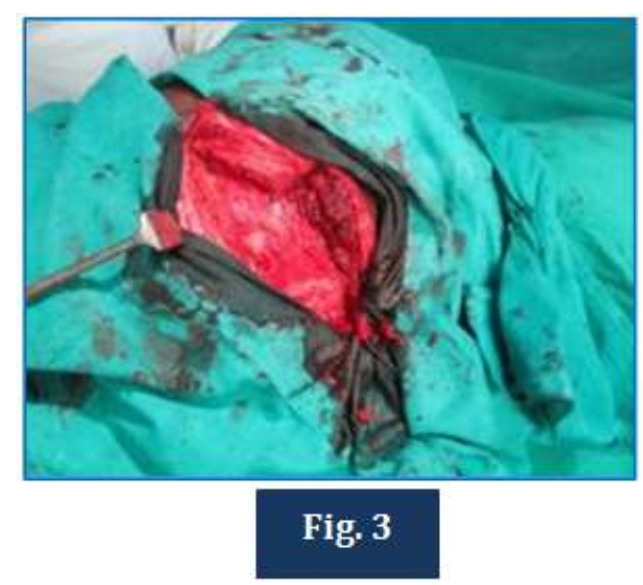

\begin{tabular}{|c|c|c|}
\hline Grade & & Clinical features \\
\hline 1 & NEGLIGIBLE & Unaware of neural deficit, Plantar extensor/Ankle clonus \\
\hline 2 & MILD & Walk with support \\
\hline 3 & MODERATE & Non-ambulatory, Paralysis in extention, sensory loss $<50 \%$ \\
\hline 4 & SEVERE & 3+ paralysis in flexion/sensory loss $>50 \%$ / Sphincters involved \\
\hline \multicolumn{3}{|c|}{ Table 1: Kumar's classification of Tuberculous paraplegia } \\
\hline
\end{tabular}

\begin{tabular}{|c|c|c|c|}
\hline Stage & & Features & Usual duration \\
\hline 1 & Pre-destructive & Straightening, spasm, hyperemia in scinti & $<3 \mathrm{mo}$ \\
\hline 2 & Early-destructive & Diminished space paradiscal erosion Knuckle $<10$ & $2-4 \mathrm{mo}$ \\
\hline 3 & Mild kyphos & $2-3$ verte $\mathrm{k}: 10-30$ & $3-9 \mathrm{mo}$ \\
\hline 4 & Moderate kyphos & $>3$ verte K:30-60 & $6-24 \mathrm{mo}$ \\
\hline \multicolumn{4}{|r|}{ Table 2 : Kumar's Clinico Radiological Classification } \\
\hline
\end{tabular}

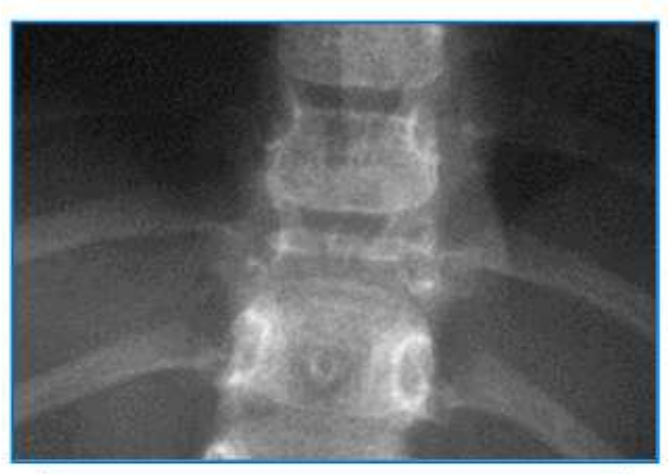

Fig.1: Collapse of vertebral body with Sparing of the disc space

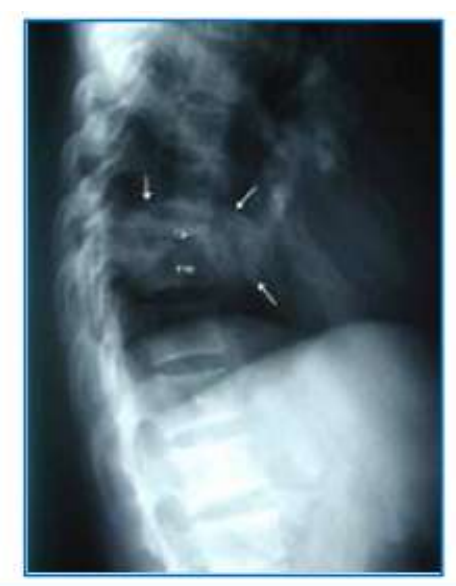

Fig.2: Anterior wedging of the bodies with pre vertebral abscess 


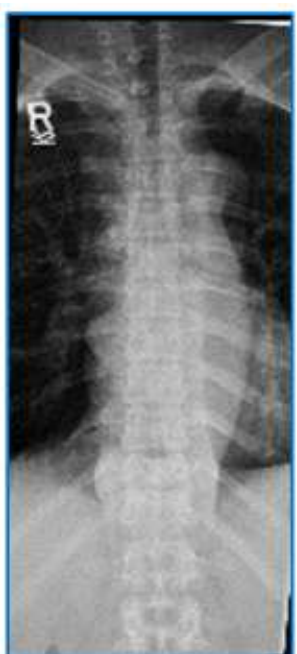

Fig. 3: Huge Fusiform Para-spinal abscess

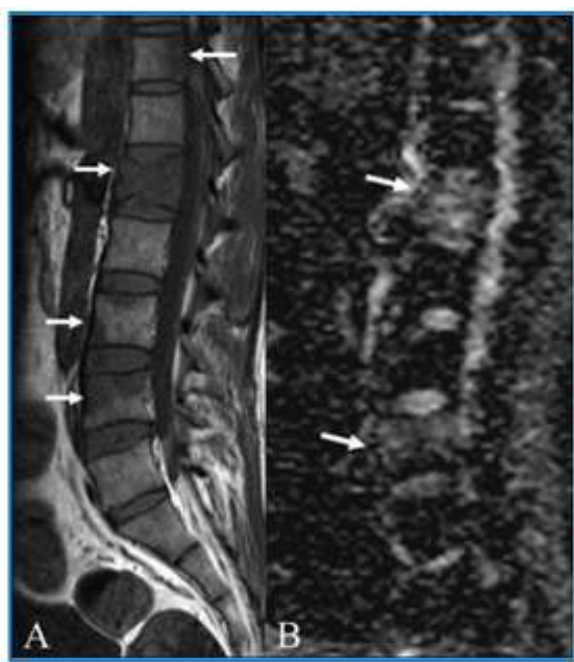

Fig. 4: MRI showing skipped lesion

\section{References:}

[1]. Barnes PF, Bloch AB, Davidson PT, Snider DE Jr. Tuberculosis in patients with human immunodeficiency virus infection. N Engl J Med 1991; 324: 1644-50.

[2]. Moon MS. Tuberculosis of the spine: controversies and a new challenge. Spine 1997; 22: 1791-7.

[3]. Greene WB, De Gnore LT, White GC. Orthopaedic procedures and progress in hemophiliac patients who are seropositive for human immunodeficiency virus. J Bone Joint Surg [Am] 1990; 72-A: 2-11.

[4]. Paiement GD, Hymes RA, La Douceur MS, Gosselin RA, Green HD. Postoperative infections in asymptomatic HIV seropositive ortho -pedic trauma patients. J Trauma 1994; 37: 545-51.

[5]. Jellis JE. Orthopaedic surgery and HIV disease in Africa. Int Orthop 1996; 20: 253-6.

[6]. Rose DN, Collins M, Kleban R. Complications of surgery in HIV-infected patients. AIDS 1998; 12: 2243-51

[7]. Frankel HL, Hancock DO, Hyslop G, et al. The value of postural reduction in the initial management of closed injuries of the spine with paraplegia and tetraplegia. Paraplegia 1969; 7: 179-92.

[8]. Govender S, Parbhoo AH. Support of the anterior column with allografts in tuberculosis of the spine. J Bone Joint Surg [Br] 1999; 81-B: 106-9.

[9]. CDC. 1993 revised classification system for HIV infection an expanded surveillance case definition for AIDS among adolescents and adults. MMWR Morb Mortal Wkly Rep 1992; 41(RR-17):19.

[10]. Bridwell KH, Lenke LG, McEnery KW, Baldus C, Blanke K. Anterior fresh frozen structural allografts in the thoracic and lumbar spine: do they work if combined with posterior fusion and instru-mentation in adult patients with kyphosis or anterior column defects? Spine 1995; 20: 1410-18.

[11]. Klein JD, Garfin SR. Nutritional status in the patient with spinal infection. Orthop Clin North Am 1996; 27: 33-6.

[12]. Govender S, Charles RW, Naidoo KS, Goga IE. Results of surgicade compression in chronic tuberculous paraplegia. S Afr Med J1988; 74: 58-9.

[13]. Wihenberg RH, Moeller J, Shea M, White AA, Hayes WC Compressive strength of autologous and allogenous bone grafts fothoracolumbar and cervical fusion. Spine 1990; 15:1073-8.

[14]. Golberg VM, Stevenson S. Natural history of auto grafts and allo-grafts. Clin Orthop 1987; 225: 7-16.

[15]. Stevenson S, Emery SE, Goldberg VM. Factors affecting bone graftin corporation. Clin Orthop 1996; 324:66-74

[16]. Stevenson S, Shafer JW, Goldberg VM. The humoral response to vascular and non-vascular allografts of bone. Clin Orthop 1996 324:86-95.

[17]. Oga M, Arizono T, Takasita M, Sugioka Y Evaluation of the risk of instrumentation as a foreign body in spinal tuberculosis: clinical and biologic study. Spine 1993; 18: 1890-4. 867.

[18]. SM Tuli, Tuberculosis of skeletal system, 4 th edition pg. $194-346$

[19]. Rejith valsalan, Efficacy of Directly observed treatment short course intermittent regimen in spinal tuberculosis.

[20]. Obaid Ur rahman, anterior surgical interventions in spinlal tuberculosis.

[21]. Pott P. Remarks on that kind of palsy of the lower limbs, which is frequently found to accompany a curvature of the spine. London. J Johnson 1779: 123-45.

[22]. World Health Organization Report 2007 Global TB Control: 125-128. Available at www. Who. Int/entity/tb/publications/ global report/2007.

[23]. Arshad M, Hussain FN, Ahmed A. Rationale for operative treatment of caries spine: a study of wenty cases. Ann K E Med Coll 2002; 8: 169-71. 